\title{
Editorial to the Special Issue „Fertility Dynamics in Austria, Germany and Switzerland"
}

\author{
Tomas Frejka, Alexia Prskawetz
}

Over the past several years, the interest for childbearing issues and trends has increased considerably among politicians, scientists, journalists and the general public in Austria, Germany and Switzerland. Low fertility and the prospects of population ageing have triggered the interest. Coverage of this topic often focused on concerns to sustain economic growth and the social welfare system. Against this background, an interdisciplinary working group of experts was established in 2009 with the aim to prepare a "state of the art"-report on "A Future with Children - Fertility and Social Development in Germany, Austria and Switzerland", conducted under the leadership of the Berlin-Brandenburgische Akademie der Wissenschaften and the Nationale Akademie der Wissenschaften Leopoldina, funded by the Jacobs Foundation. Contrary to the "deficit-oriented" viewpoint of having too few children, the aim of the group was to offer a constructive, future-oriented discussion on the causes of low fertility in the three countries, Austria, Germany and Switzerland. Four subgroups were established focusing on the following topics: "History and Theory of Population Development", “Demographic Analysis of Fertility Development", "Family Development and Policy, and Medical Aspects of Fecundity and its Relevance for Society". The report, which was finalised in autumn 2011, will be published by Campus under the title "Zukunft mit Kindern. Fertilität und gesellschaftliche Entwicklung in Deutschland, Österreich und der Schweiz" (Stock et al. 2012). The book includes chapters on "Fertility in a Historical Perspective", "Theories of Fertility", "Demographic Analysis of Fertility Developments", "A Family Policy for Children and Parents", "Medical and Biological Aspects of Fertility" and summary chapters reviewing myths and legends, main messages, and recommendations.

The goal of this CPoS volume is to discuss important fertility trends in Austria, Germany and Switzerland. Results of the research undertaken by the subgroup "Demographic Analysis of Fertility Development" are presented. For most of the past century, cohort and period fertility in Austria, Germany and Switzerland were among the lowest in Europe, especially compared to other West European countries. This is true notably since the early 1970s. A number of fertility related issues are explored: women's parity distribution, childlessness, the correlation of fertility and education and the effect of migration on fertility. Special attention is devoted to the quality and availability of fertility data, the changing age structure of fertility, the number of children women desire, the effects of low fertility on changes in the 
population age structure, the spatial variation of sub-national fertility trends and the role of fertility assumptions in population projections.

In the first paper, Tomáš Sobotka performs a thorough demographic analysis of childbearing trends in the three German-speaking countries while focusing on the question posed in the title of the paper: Is there a common fertility pattern in these three countries? In general, the answer is positive. But there are also significant differences, especially between Eastern and Western Germany. The relatively low fertility in the three countries is mainly due to high levels of childlessness and low fertility intentions, particularly among better-educated women. Over the past four decades, total fertility rates have been around 1.5 births per woman. Total cohort fertility rates have been marginally higher than period rates, indicating an ongoing moderate trend of childbearing postponement. Cohort parity distribution trends indicate a continuation of the two-child family model. However, in Eastern Germany, the one-child family model steadily increases. At the same time, childlessness is on the rise in the three countries, reaching levels of above $20 \%$. Sobotka argues that completed fertility is likely to stabilise at the level of approximately 1.6 births per woman. An ongoing retreat of marriages and a shift to cohabitation, non-residential partnerships (LAT), single living, and a prolonged stay in the parental home, all inevitably lead to an increasing number of children born out-of-wedlock. In its effect on total fertility, the negative educational gradient is intensified by a declining share of women with no or only elementary education. Relatively high childbearing among immigrants has a moderate positive effect on total fertility. In the European context, Austria, Germany and Switzerland have an older population, lower fertility, slower population growth, later childbearing and higher levels of childlessness. These demographic features are linked with historically intrinsic societal structures, such as a strict division of gender roles in childrearing, long withdrawal of mothers from the labour market, perceived difficulties of combining work and family life, a negative perception of working mothers and childcare during the first three years of a child's life.

The quality and availability of data are discussed in the second paper by Michaela Kreyenfeld, Kryštof Zeman, Marion Burkimsher and Ina Jaschinski. A lack of long series of data from registration systems of live births, in particular by biological birth order, as the base for deriving fertility measures, is the main problem in all three countries. Reforms to address this issue were implemented in Austria in 1984, in Switzerland in 1998 and in Germany in 2008. Other sources of data used for analysing fertility are censuses, micro censuses and surveys. Detailed reviews and evaluations are presented for each country. Comparing the available data of the three countries, Germany stands out with several high quality panel studies. In Austria, the quality of population statistics is very good and long-enough series of data for analysis will soon be available due to the reforms of 1984. In Switzerland, however, such data only became available as late as 2006 , and there is a lack of surveys. The authors suggest that the introduction of population registers containing fertility and migration histories would provide a solid base for fertility investigations. At present, relevant data for all three countries are assembled in the Human Fertility Database 
of the Max Planck Institute for Demographic Research and the Vienna Institute of Demography.

In the third paper, Tomáš Sobotka, Kryštof Zeman, Ron Lesthaeghe, Tomas Frejka and Karel Neels introduce improved methods for analysing cohort childbearing postponement (fertility decline at young ages) and recuperation (a compensatory fertility increase at older reproductive ages). The analytical methods are then used for developing new projection scenarios. This work deals with two models: the basic benchmark model elaborated by Frejka and associates and the relational model developed by Lesthaeghe. These new analytical methods focus on the importance of selecting appropriate base cohorts, on the need for separate order-specific analyses, and on the correct identification of the age of maximum decline of the cumulated childbearing rates compared to the base cohort. Contemporary cohort fertility differences between populations are explained by three key indicators of the postponement transition: the initial fertility level, the absolute fertility decline at younger ages, and the relative degree of fertility recuperation at older ages. In Austria, Germany and Switzerland, the tendency of recuperation, of third and higher order and even of second order, was relatively weak compared to other West and North European populations, which explains much of the low fertility in these countries. It appears that fertility will remain relatively stable in these three countries in the near future. The 1980 Completed Cohort Fertility Rate (CCFR) was projected at about 1.6 births per woman for Austria and at about 1.55 for Switzerland. For Germany, comparable data were not available, but it can be assumed that the projected 1980 CCFR is likely to be at a similar level.

The measurement of reproductive decisions is discussed in the fourth paper by Dimiter Philipov and Laura Bernardi. It focuses on the operationalisation of two measures: fertility ideals and fertility intentions. In distinction to many other analyses of fertility ideals and intentions, the unique contribution of this paper is to offer a discussion on the validation of the concepts. Based on various surveys in Austria, Germany and Switzerland, the authors present estimates of ideal and intended fertility and compare it to actual fertility. Although several ambiguities may arise in the question on ideals, the authors argue that those questions should not be left out, as recently happened in several other surveys. Instead, better formulations of the relevant questions should be designed. The difference between fertility ideals/intentions and actual fertility is often used to promote more active family policies that help to close the gap. However, the fertility gap itself may be wrongly measured, if cohort and period measures are compared. A further ambiguity arises through the ecological fallacy by interpreting a macro-level phenomenon, such as the fertility gap, as a micro-level childbearing "gap".

A theoretical and empirical study of regional fertility differentials is the focus of the fifth paper by Stuart Basten, Johannes Huinink, and Sebastian Klüsener. The theoretical discussion deals with spatial and compositional contextual factors influencing spatial fertility differentials. These include the material and institutional infrastructure, economic conditions and prospects in the local labor market, sociostructural factors in the area of residence, cultural factors which contribute to a localised social climate and embeddedness in local social contexts. The empirical 
analysis demonstrated that at the macro-regional level the overall fertility trends in Austria, (Western and Eastern) Germany and Switzerland have been characterised by a process of convergence in recent decades. At the micro-regional level, fertility trends may very well diverge. Such was the case in the study conducted in the city of Bremen.

In the final chapter, Joshua R. Goldstein, Felix Rößger, Ina Jaschinski and Alexia Prskawetz review the assumptions for future fertility trends that formed the basis of population projections in Austria, Germany and Switzerland in recent decades. Overall, the analytic procedure was to assume the persistence of the present total fertility rate. In general, this is considered reasonable. At the same time, the authors argue and explicitly demonstrate that fertility forecasts were inconsistent regarding assumptions on changes in the mean age of childbearing, the level of fertility and projections of the period total fertility rate. While statistical offices project a stagnation in the increase of the mean age at first child birth in the future, this trend was not reflected in the projected levels of total fertility rates. Suggestions of how to improve fertility projections are outlined. On the basis of fertility projections for Germany, it is demonstrated how a consistent interrelation of an increase in period fertility and its convergence to cohort fertility can be modeled, when postponement of fertility in older age groups comes to a halt.

This volume represents an up-to-date compendium of fertility dynamics in Austria, Germany and Switzerland, including a thorough discussion of measurement issues and an analysis of projection methods.

Concerning fertility dynamics, the following fundamental observations are highlighted by the expert group: The difference between cohort and period fertility needs to be understood and communicated. When births are being postponed, there are less of them per year, i.e. period fertility is deflated. This is what has been happening in recent decades. All three countries have experienced a considerable decline of period fertility rates to levels between 1.4 and 1.6 between the mid-1960s through to the mid-1980s; they are among the countries with the lowest fertility in Europe. The fertility rate of cohorts born in 1968 was 1.6 in Austria, 1.7 in Switzerland and 1.5 in Germany. Fertility differentials between countries have declined, and this convergence was even faster between regions within countries. The effect of immigrant fertility on overall period fertility is lower than generally perceived by the public and is in the order of 0.05 to 0.12 children per woman in most European countries. The postponement of childbearing to higher ages has not been followed by a recuperation of fertility to the same extent as in other European countries. Fertility intentions are lower as compared to other countries in Europe. However, measurement of fertility intentions and the fertility gap are often imprecise, as they rely on flawed concepts of fertility intentions and falsely compare cohort levels of fertility with observed period measures of fertility. Fertility projections are key ingredients for any population projections. The current practice of fertility projections often lacks a clear distinction between quantum and tempo assumptions on fertility. 


\section{Acknowledgements}

This publication was generated in the context of the interdisciplinary working group Future with Children - Fertility and the Development of Society. This group has been jointly established by the Berlin-Brandenburgische Akademie der Wissenschaften and the Nationale Akademie der Wissenschaften Leopoldina and is funded by the Jacobs Foundation. As guest editors of the special issue we are particularly grateful to Ina Jaschinski for proofreading all papers and assisting in the German translation.

\section{Reference}

Stock, Günter; Bertram, Hans; Fürnkranz-Prskawetz, Alexia; Holzgreve, Wolfgang; Kohli, Martin; Staudinger, Ursula M. 2012: Zukunft mit Kindern. Fertilität und gesellschaftliche Entwicklung in Deutschland, Österreich und der Schweiz. Campus. Frankfurt.

Tomas Frejka und Alexia Prskawetz $(\bowtie)$. Vienna Institute of Demography of the Austrian Academy of Sciences, Wittgenstein Centre for Demography and Global Human Capital and Vienna University of Technology, A-1040 Vienna, Austria.

E-Mail:Tfrejka@aol.com; Alexia.Fuernkranz-Prskawetz@oeaw.ac.at

URL: http://www.oeaw.ac.at/vid/staff/staff_alexia_fuernkranz.shtml 


\section{Comparative Population Studies - Zeitschrift für Bevölkerungswissenschaft}

wWw.comparativepopulationstudies.de

ISSN: 1869-8980 (Print) - 1869-8999 (Internet)

Published by / Herausgegeben von

Prof. Dr. Norbert F. Schneider

Federal Institute for Population Research

D-65180 Wiesbaden / Germany

Managing Editor /

Verantwortlicher Redakteur

Frank Swiaczny

Editorial Assistant /

Redaktionsassistenz

Katrin Schiefer

Language \& Copy Editor (English) /

Lektorat \& Übersetzungen (englisch)

Amelie Franke

Copy Editor (German) /

Lektorat (deutsch)

Dr. Evelyn Grünheid

Layout / Satz

Sybille Steinmetz

E-mail: cpos@destatis.de

\author{
Scientific Advisory Board / \\ Wissenschaftlicher Beirat \\ Jürgen Dorbritz (Wiesbaden) \\ Paul Gans (Mannheim) \\ Johannes Huinink (Bremen) \\ Marc Luy (Wien) \\ Clara H. Mulder (Groningen) \\ Notburga Ott (Bochum) \\ Peter Preisendörfer (Mainz)
}

\section{Board of Reviewers / Gutachterbeirat} Martin Abraham (Erlangen) Laura Bernardi (Lausanne) Hansjörg Bucher (Bonn) Claudia Diehl (Göttingen) Andreas Diekmann (Zürich) Gabriele Doblhammer-Reiter (Rostock) Henriette Engelhardt-Wölfler (Bamberg) E.-Jürgen Flöthmann (Bielefeld) Alexia Fürnkranz-Prskawetz (Wien) Beat Fux (Zürich) Joshua Goldstein (Rostock) Karsten Hank (Köln) Sonja Haug (Regensburg) Franz-Josef Kemper (Berlin) Michaela Kreyenfeld (Rostock) Aart C. Liefbroer (Den Haag) Kurt Lüscher (Konstanz) Dimiter Philipov (Wien) Tomáš Sobotka (Wien) Heike Trappe (Rostock) 